\title{
Communicable Diseases Report, NSW, January and February 2010
}

\section{Communicable Diseases Branch NSW Department of Health}

For updated information, including data and facts on specific diseases, visit www.health.nsw.gov.au and click on Public Health and then Infectious Diseases. The communicable diseases site is available at: http://www.health.nsw.gov.au/publichealth /infectious/index.asp.

Figure 1 and Tables 1 and 2 show reports of communicable diseases received through to the end of January and February 2010 in New South Wales (NSW).

\section{Meningococcal disease}

In January, 8 cases of meningococcal disease were reported in NSW and in February, 4 cases were reported. Of these 12 cases, 9 were due to serogroup B infection, none were due to serogroup $\mathrm{C}$ infection and 3 were not able to be typed. The ages of these people ranged from 2 months to 24 years; $67 \%$ were males and 10 lived in regional NSW. Twelve cases were reported for the same period in 2009. In NSW in $2009,80 \%$ of cases of meningococcal disease (where the serogroup was known) were caused by serogroup B, for which there is no vaccine.

For national guidelines for the early clinical and public health management of meningococcal disease, please see: http://www.health.gov.au/internet/main/publishing.nsf/ Content/cda-pubs-other-mening-2007.htm.

\section{Hepatitis A cluster}

In January and February, the Population Health Unit of Hunter New England Area Health Service investigated 9 cases of hepatitis A with links to a primary school. Four children from the same class appear to have acquired their infection from an unidentified source. Five further cases of hepatitis A were reported from close contacts of these cases. None of the children have reported travel overseas and household contacts of these children have received hepatitis A vaccination as a precaution. The Population Health Unit provided advisory letters to families with children in the class, and advice was also provided to other families at the school through the school newsletter.

Hepatitis A is a virus transmitted almost entirely by the faecal-oral route (e.g. eating contaminated food, drinking contaminated water, or direct transfer or direct contact with a person with the infection). The incidence of hepatitis A infection has declined in the last few decades in most parts of Australia, possibly related to improved water supplies, safer food handling practices, improved hygiene and availability of a vaccine. Most cases in NSW are acquired overseas in countries where there is poor sanitation and hygiene. A safe and effective vaccine is available that provides long-term protection against hepatitis A infection.

\section{Salmonellosis}

In January, the Population Health Unit of Greater Southern Area Health Service, in collaboration with the NSW Food Authority (NSWFA), investigated an outbreak of Salmonella infection involving people who ate food from a fast food outlet in Albury. Over 170 people reported gastroenteritis and were interviewed about food consumption. Ninety-eight had confirmed Salmonella infection. All cases had eaten food from the outlet between 14 and 19 January 2010. The NSW Food Authority and Albury Council inspected the outlet, examined food safety practices and sampled foods and the environment for laboratory testing. Salmonella was isolated from aioli (a sauce) and a cutting board located at the premises. The NSW Food Authority issued a prohibition order that prevented the premises from operating until the NSW Food Authority determined that it had met all requirements for a clearance certificate to be issued.

In February, NSW Health began epidemiological investigations into increases in notifications of infection with two distinct types of Salmonella $-S$. Infantis (20 cases in January and 28 in February) and of $S$. Potsdam ( 9 cases in January and 2 in February). The people affected are widely geographically distributed and there is also no significant clustering by age or sex. Investigations are ongoing.

Salmonellosis is caused by infection with Salmonella bacteria. In Australia, most salmonellosis is caused by eating contaminated food or sometimes through contact 
with another person with the infection. Symptoms commonly include headache, fever, stomach cramps, diarrhoea, nausea and vomiting that start 6-72 hours after infection and last for 4-7 days, although sometimes much longer.

\section{Measles}

In January, a case of measles was reported in an unimmunised child returning from travel overseas. The child was infectious during the international flight and passengers seated in the surrounding rows were contacted by public health staff to help contain further transmission. Passengers who were identified as not immune to measles were advised to receive a second dose of measles-containing vaccine MMR.

In February, 4 new cases of measles were reported. Three of these people were unimmunised siblings of the child who first developed measles in January. These children had been quarantined at home since January. Another case was reported in a child who sat in the row behind the index case on the plane.

In addition, the Department of Health in Victoria notified NSW of a case of measles in a tourist who had visited NSW and Queensland during his infectious period. The person visited a youth hostel and a restaurant in Sydney. No secondary cases were reported.

Most cases of measles in NSW are seen in travellers who return with the infection from countries where measles is endemic after having been exposed to a known case. Many people who were born since 1966 and before the mid 1980s are not immune to measles because they have neither been infected with measles nor received two doses of a measles vaccine. Measles vaccine is now routinely given to infants at 12 months and at 4 years of age, and this confers longlasting immunity.

\section{Chickenpox and shingles surveillance}

Chickenpox is a viral illness caused by the herpes zoster virus (also known as the Varicella-Zoster virus). Shingles is caused by the reactivation of the virus that causes chickenpox, usually in adulthood and many years after the initial chickenpox illness. The virus can be spread by direct contact with the skin rash of people with the infection. This causes chickenpox in people who are not immune. Shingles develops more commonly in people who are immunosuppressed.

Before routine childhood vaccination began in 2006, chickenpox was a very common illness. In NSW, the incidence of infection is monitored through the number of patients attending emergency departments with chickenpox or shingles. Updated data are now routinely available for emergency department visits of NSW residents assigned a diagnosis of chickenpox or varicella infection (see: http://www.health.nsw.gov.au/data/diseases/chicken pox.asp and http://www.health.nsw.gov.au/data/diseases/ shingles.asp).

In January, an increase in presentations for shingles was reported by some emergency departments in NSW. The median age of people presenting and assigned a diagnosis of shingles or herpes zoster disease was 59 years (range 4-97 years). Of these, 53\% were female. In the same period, a slight increase was reported for presentation of chickenpox. The median age of people presenting and diagnosed with varicella or chickenpox was 8 years (range 0-83 years). Of these people, $48 \%$ were female.

\section{Anthrax}

In February, a case of cutaneous anthrax was reported in a farmer who worked on a sheep property in south western NSW located in NSW's anthrax belt, an area stretching down the middle third of the state where anthrax spores are present in the soil. In the days prior to onset, a farmer reported doing some fencing work on the property that most likely disturbed the soil that contained anthrax spores. The diagnosis was suspected on clinical grounds and was confirmed by laboratory tests.

Cutaneous anthrax is very rare in NSW. Bacterial spores in affected soil get into small skin cuts or wounds where they germinate and cause skin ulceration and surrounding swelling. The skin ulcer develops a characteristic black area of dead tissue. With treatment, patients generally make a full recovery.

\section{Gonorrhoea}

Notifications of gonorrhoea increased in January, when 239 cases were notified in NSW; of these, $85 \%$ were men. Based on previous epidemiological patterns, a large proportion of these people are likely to be men who have sex with men. NSW Health worked with partner agencies to publicise safer sex messages to high-risk communities during the Mardi Gras festival. In 2009, 1658 cases were notified in NSW, an average of 138 cases per month.

\section{Influenza activity}

Little influenza activity was reported in NSW in January and February. The weekly number of patients presenting to emergency departments with influenza-like illness remains steady at near baseline levels. 
Figure 1. Reports of selected communicable diseases, NSW, January 2004 to February 2010, by month of onset. Preliminary data: case counts in recent months may increase because of reporting delays. Laboratory-confirmed cases only, except for measles, meningococcal disease and pertussis. BFV, Barmah Forest virus infection; RRV, Ross River virus infections; lab conf, laboratory confirmed; Men $\mathrm{Gp} C$ and $\mathrm{Gp} B$, meningococcal disease due to serogroup $C$ and serogroup $B$ infection; other/unk, other or unknown serogroups.

NB: Multiple series in graphs are stacked, except gastroenteritis outbreaks.

NB: Outbreaks are more likely to be reported by nursing homes $\&$ hospitals than by other institutions.

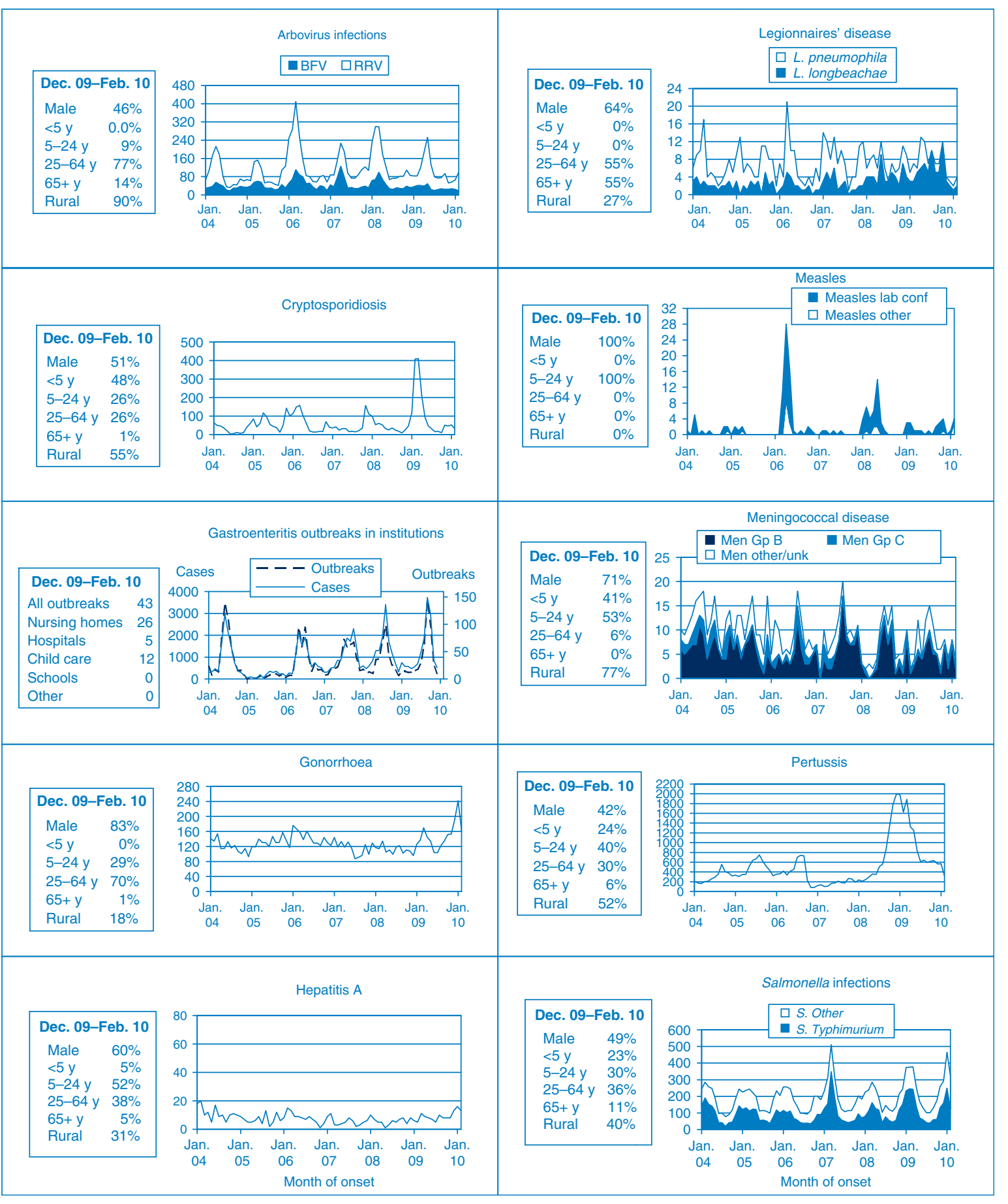




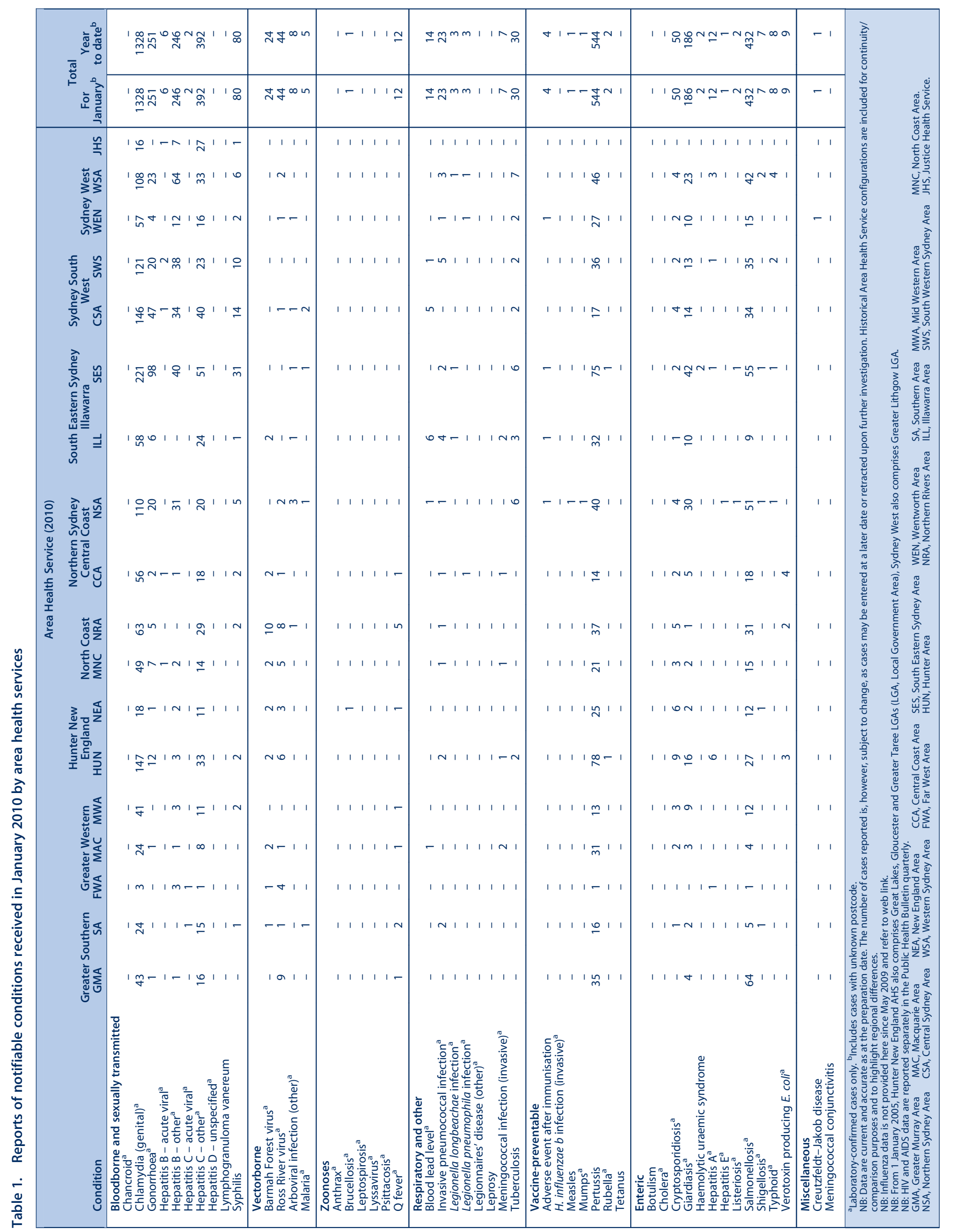

106 | Vol. 21(3-4) 2010 NSW Public Health Bulletin 


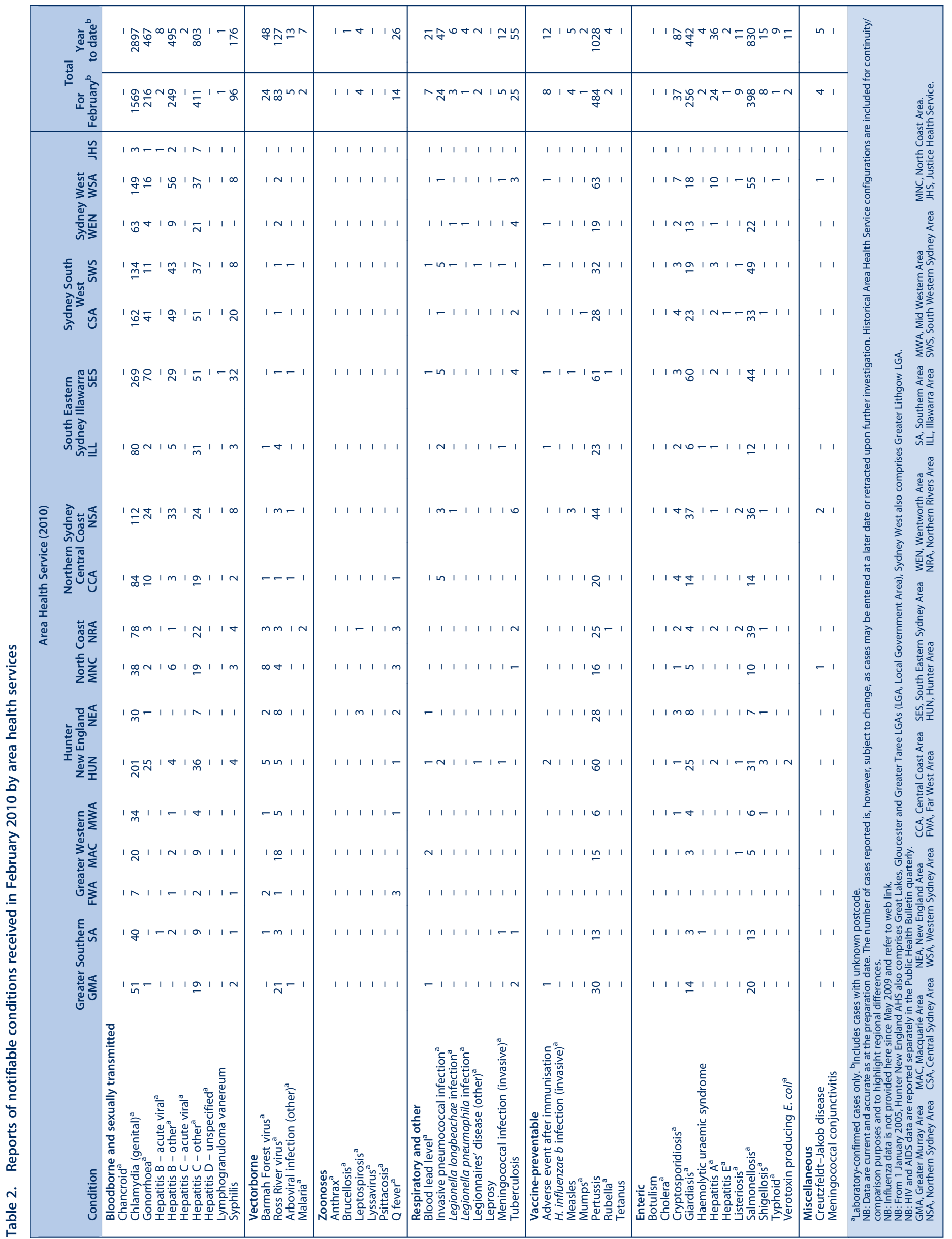

